Issledovatel'skiy Zhurnal Russkogo Yazyka i Literatury, Vol. 9, Issue 2, 2021, Pp: 151-167

DOI: 10.52547/iarll.18.151～DOR: 20.1001.1.23452498.2021.9.2.8.6

Article No.: 18.81.20212.151167

Scientific Article

\title{
The Heavenly Flame: The Christian Picture of the World and Modeling of the Image in the Literary Text
}

\author{
Zakharova Nadezhda Nikolaevna ${ }^{1 *}$ \\ Associate professor of the Tula State University, \\ Tula, Russia. \\ (date of receiving: May, 2021; date of acceptance: June, 2021)
}

\begin{abstract}
A word in a literary text can acquire the character of a symbol, since its macrosemantics includes semantic connotations containing, in a compressed form, elements of the semiotic space of Christian culture. This article is devoted to the study of the semantics of the lexical unit «пламень» - «flame», which in Russian serves as one of the ways to verbalize the emotions and interpersonal relationships, contains the image of the heavenly flame as the Divine light of a righteous soul and a punishing sword for a soul mired in sin. When it included in a literary text, this lexical unit "gives" the growth of meaning to the literary text, expands its semantics. The interpretation of such a text is an attempt to construct a certain trajectory along a semantic grid of coordinates, where the key points are symbols as codes of the national culture and the Christian worldview.
\end{abstract}

Keywords: Lexical Semantics, Macrocomponent's Structure of Semantics, Lexical Unit, Literary Text, Christian Worldview, Symbol.

1. E-mail: nadine1967@mail.ru * Corresponding author 
Issledovatel'skiy Zhurnal Russkogo Yazyka i Literatury, Vol. 9, Issue 2, 2021, Pp: 151-167

DOI: $10.52547 /$ iarll.18.151 DOR: 20.1001.1.23452498.2021.9.2.8.6

Article No.: 18.81.20212.151167

\title{
Пламень небесный: христианская картина мира и образомоделирование в художественном тексте
}

\author{
Захарова Надежда Николаевна ${ }^{1 *}$ \\ Доцент, Тульский государственный университет, \\ Тула, Россия. \\ (дата получения: май 2021 г.; дата принятия: июнь 2021 г.)
}

\begin{abstract}
Аннотация
Слово в художественном тексте может приобретать характер символа, поскольку ее макросемантика включает в себя семантические коннотации, содержащие в сжатом виде элементы семиотического пространства христианской культуры. Данная статья посвящена изучению семантики лексической единицы пламень, которая в русском языке служит одним из способов вербализации эмоций и межперсональных отношений, содержит в себе образ небесного пламени как Божественного света для души праведной и карающего меча для души, погрязшей в грехе. При включении в художественный текст данная лексическая единица «отдает» наращения смысла художественному тексту, расширяет его семантику. Интерпретация такого текста - попытка построения некой траектории по семантической сетке координат, где ключевыми точками выступают символы как коды национальной культуры и христианского мировидения.
\end{abstract}

Ключевые слова: Лексическая Семантика, Макрокомпонентная Структура Семантики, Лексическая Единица, Художественный Текст, Христианская Картина Мира, Символ.

1. E-mail: nadine1967@mail.ru * Ответственный автор 


\section{Введение}

Как известно, одной из стилистических классификаций лексического фонда русского языка является понятие книжности, которое выводится из совокупности его признаков как торжественное, приподнятое, употребляемое преимущественно в письменной форме реализации языка и принадлежит сфере интеллектуального общения. За этим, на наш взгляд, стоят более глубокие основания: книжность предполагает апелляцию к определенному дискурсу и использование его семиосферы и аксиологии. Книжная лексическая единица вбирает в себя смыслы и образы, которые транслируются из этой семиосферы в национальное сознание и национальную языковую картину мира, поэтому книжная единица, включаясь в художественный текст, становится символом, подключающим к тексту те или иные семантические пласты, содержащиеся в когнитивном образе.

\section{Основная часть}

Слово пламень во всех толковых словарях соотносится со словом пламя, в том числе и в переносном значении - 'пыл, воодушевление. Пламя гнева' (Словарь русского языка: Т. 3), при этом указывается на книжную, традиционно-поэтическую маркированность данной лексической единицы. Однако стилистическая коннотация слова не ограничивается книжностью как сферой употребления и соотносится с христианской картиной мира и библейской образностью. В словарях указывается лишь одно из метафорических значений слова - выражение душевного подъема. Проанализируем более детально, какие культурологические, стилистические, образные коннотации содержит макрокомпонентная структура семантики данного слова. В статье приводятся примеры того, что значение лексемы пламень как обозначение интенсивности силы, жизненной энергии или 
духовной мощи человека также имеет семантическую связь и семантическую преемственность от «небесного пламени», даруемого Господом воину как доблесть и бесстрашие, поэту - как вдохновение, любящему - как самоотверженность и жертвенность.

Лексическая единица пламень организует концептуальное поле эмоций в русском языке и участвует в метафорической вербализации представления об эмоциях как стихии огня, которая может быть гибельной для человека. Многочисленны контексты употребления единицы для обозначения враждебных межперсональных отношений: «И хотя из-за неожиданного и коварного дедова решения внешне ничего не переменилось и новая хозяйка не торопилась устанавливать свои порядки, предусмотрительная бабушка на всякий случай сочинила и заверила в правлении товарищества с юридической точки зрения сомнительную, но всё же защищавшую интересы старшего сына бумагу, благословила его на строительство собственного домика и на время сумела пригасить взметнувшийся пламень родовой вражды» (А. Варламов. Купавна // НКРЯ). - «Когда старое сердце преисполнялось восторга, благоволения, мира, но в потаенной его глубине кипела обида и жгло, как пламя, сознание бессилия пред клеветой и завистью; когда этот пламень усмирялся лишь двумя мыслями: о Боге и о суде истории. (В.Ф. Ходасевич. Державин // НКРЯ).

Гибельность для человека отрицательных эмоций - обиды, зависти, ненависти, фанатизма - означивается как адский огонь и соотносится с темой посмертного наказания адским котлом, поскольку нелюбовь к ближнему в христианской картине мира является греховным проявлением. Сообразными выглядят попытки человека «усмирить», «погасить» демоническую стихию огня молитвой, мыслями о Боге и смирении. Даже яростная любовь как страсть представляется страданием, гибельным души, отречением от Божественной чистоты и целомудрия. Использование метафорической 
ипостаси пламени размещает негативные эмоции-страсти на нижней точке вертикали, направленной к Божественной высоте. Высшей координатой является смирение и тишина сердца: «Илларион грозил, что адский пламень неугасим, и она не раз созерцала в церкви картину Страшного суда: на ней праведники веселились, а грешников пожирал огромный зеленый сатана, и у него из розовой пасти вырывались желто-красное пламя и дым; другие крошечные человечки мучались в котле с кипящей смолой, некоторых пронзали трезубцами хвостатые черти» (А.П. Ладинский. Анна Ярославна королева Франции // НКРЯ). - «Да крестись и хоть шепотом, повторяй за мной: "... неразумие, нерадение и вся скверна, лукавая и хульная, помышления от окаянного моего сердца и от помраченного ума моего, и погаси пламень страстей моих, яко нищ есмь и окаянен"» (В. Астафьев. Последний поклон // НКРЯ).

В противовес адскому пламени пламень небесный предстает в христианской картине мира огнем очищающей молитвы, мечом архангела, уничтожающим мировое зло. Сердце, полное любви к Господу, представлено когнитивной моделью как емкость, наполненная небесным огнем, а вера - как согревающее человеческую душу тепло, дающее жизнь в этом мире и обещающее жизнь вечную, поскольку этот огонь мыслится как субстанция сакральная, полученная от неопалимого небесного пламени-света: «Дней через пять он начал чувствовать сильную теплоту и... по временам он начал видеть свет... иногда представлялось ему, когда он входил в сердце, что как бы сильный пламень зажженной свечи вспыхивал сладостно внутри сердца и выбрасываясь через горло наружу, освещал его; и он при сем пламени мог видеть даже и отдаленные вещи» (А.И. Осипов. Учение о молитве Иисусовой святителя Игнатия (Брянчанинова // НКРЯ). - «Но утешает его пламень любви к ближнему, разгорающийся в сердце с годами всё ярче, отрадней» (В.Г. Галактионова Спящие от печали // НКРЯ). - «Ведь для того, чтобы так 
подвизаться, как подвизался преподобный Серафим, для того чтобы молиться тысячу дней и ночей, для того чтобы нести такой пост, для того чтобы быть исполненным такого смирения, - для всего этого нужно, чтобы в сердце постоянно горел пламень огненный» (В.П. Свенцицкий. Преподобный Серафим // НКРЯ).

Согласно богословскому словарю, в Библии имеется более 400 словесных упоминаний огня в символико-божественном аспекте, которые восходят к пламенному мечу херувима, преграждающему Адаму путь в рай (Быт. 3:24). В этом дуалистический характер понимания Божественного огня, который для верующих служит светом согревающей молитвы, знаком присутствия Бога, а для грешника становится карающей силой: в День Суда «придет Господь в огне» и «огнем и мечом Своим произведет суд над всякою плотью» (Ис. 24:6; 66:15,16). В огненное озеро ввергаются «смерть и ад» (Откр. 20:14). Падшие ангелы сгорят в огне Судного Дня (Мф. 25:41) (Цит. по: Охоцимский // Иеротопия).

Несомненно, что следующее значение лексемы пламень как обозначение интенсивности силы, жизненной энергии или духовной мощи человека имеет семантическую связь и семантическую преемственность от «небесного пламени», даруемого Господом воину как доблесть и бесстрашие, поэту - как вдохновение, любящему - как самоотверженность и жертвенность: «Тончайший пламень, занявшийся в груди под густой меховой порослью, возможно, так и остался бы не замеченным самим Алексеем Кирилловичем, если бы Сандрочка не почувствовала притяжения к этому профессору, забавному и старомодному, и не раздула этого неопределенного, чуть тлеющего интереса» (Людмила Улицкая. Медея и ее дети // НКРЯ).

Советский литературовед М.О. Гершензон, исследуя поэзию А.С. Пушкина, отмечает, что для поэта вдохновение и талант равносильны божественному горению. Творчество поэта как посланника Бога на земле, как 
гения (исходя из древнегреческого представления гения как духа, посредника между Небом и людьми) есть святое горение, самопожертвование, служение, а способность творить красоту осознается как святое предназначение передавать очищающий пламень небесный и Божественную истину всем людям. Цитируя А.С. Пушкина, М.О. Гершензон справедливо утверждает, что поэт «самую обитель Бога, небесные селения» «определяет как пламя» («Где чистый пламень пожирает несовершенство бытия») (Гершензон 1990. 215).

Уподобление истинной, полнокровной жизни концептуально уподобляется горению пламени: «Смотрите на пламень его - это жизнь Человека» (Л.Н. Андреев. Жизнь Человека // НКРЯ). При этом за интенсивностью и энергетикой жизни всегда прозревается божественная, до конца недоступная сознанию человека тайна бытия, открытая в своей вещественности в красоте и наполненности мира тварного, но не рукотворного: «... значит, весь этот город со мною уже навсегда, он порывисто дышит, ворочается, набухает сгусток жизни, хранитель традиций, разомкнутый круг, дух, парящий над миром, немеркнущий пламень, магический шар, сфинкс, молчащий о прошлом, грядущий рассвет, нескончаемый дар» (В.Д. Алейников. Тадзимас // НКРЯ).

Не только в книжной культуре, но и в обыденном сознании и энергетика и интенсивность жизни (и в то же время как оборотная сторона - ее же быстротечность) определяются как горение. И этот образ исходит из библейского представления об огне жертвенном, служащим проводником к Божественной милости. Возникает метафора, уподобляющая яркую, интенсивную жизнь человека забираемой Богом святой жертве.

В сложном полисемантическом, насыщенном интертекстуальными связями художественном тексте, принадлежащем литературе конца XX - начала XXI вв., часто используются символы, подключающие к семиотическому пространству текста собственную семиосферу. Символ обладает способностью развертывания в сложнейший культурный текст, фокусирующий в себе 
знание, выработанное человеческой цивилизацией, получившее означивание в различных формах культуры - литературе, музыке, живописи, а также существующее в когнитивном пространстве культурно ориентированной личности как система концептов. Введение в текст культурных символов расширяет семиотическое пространство текста и вместе с этим значительно увеличивает вероятностные интерпретации художественного текста, делает их зависимыми от «культурной состоятельности» читателя. В художественном пространстве каждый элемент координирует со всем целым и «настраивается» на когезию с семантикой другого элемента данной системы, результатом чего становится индивидуально-авторское семиотическое пространство. Интерпретация такого текста - попытка построения некой траектории по семантической сетке координат, где ключевыми точками выступают символы, находящиеся на ключевых позициях художественного текста (заголовок, начало и конец текста, повторяемость в сюжетных действиях).

Рассказ Т. Толстой «Пламень небесный» можно рассматривать как историю, вырванную из жизни, в которой почти в чеховской манере запечатлены «мелочи жизни»: это непритязательная история о том, как сплетня, кинутая в сознание «милых» собеседников из неведомо каких побуждений, меняет полюс отношения к одному из персонажей. Но что-то встает за этим большее и горшее, чем присутствует в сюжете. Что же? Библейские образы, которые путеводными знаками уводят повествование в категорию вечности. И одним из таких знаков является символ пламень небесныцй, введенные в ключевую позицию текста - название рассказа - и повторяющийся в самом тексте.

Пламень небесный - нерукотворный и неопаляющий столп света, который знаменует собой явленность Бога миру и человеку, указующий на эту связь, дающий человечеству надежду на продолжение жизни в вечности: «И явился ему ангел Господень в пламени огня из среды тернового куста. И увидел он, 
что терновый куст горит огнем и куст не сгорает» (Исход. 3:2). О нем упоминается в Ветхом Завете как об огненном столпе, чудесном знамении, сопровождавшем исход евреев из Египта: «Господь же шел пред ними в столпе облачном, показывая им путь, а ночью в столпе огненном, светя им, дабы идти им и днем и ночью» (Исход. 13:21). В христианской символике пламень небесный становится символом Св. Духа, который в образе языков пламени снизошел на апостолов в день Пятидесятницы (Троицы) (Деяния, 2: 1-4). Словосочетание пламень небесный, употребляемое в рассказе Т. Толстой, почти повторяет текст прокимна праздничных богослужений («Творяй Ангелы своя духи и слуги своя пламень огненныци») и вместе с этим актуализует иконографические образы. Неопалимая купина (Исх. 3:2-4) показывает, что душа, освященная Божественным огнем веры, есть нетленная материя, это образ бессмертия. Пламень небесный содержит в себе божественную тайну, чудо, к коему стремится человеческая душа. Именно этих таинственных знаков участия сакральной силы в делах человеческих ищет в рассказе Т Толстой душа умирающего Коробейникова во всех, самых незначительных, фактах, необъяснимых наукой. Поиски сверхъестественного, мистического это попытка человека вообразить, вымыслить, обнаружить диалог с тем, что даст спасение от хаоса и равнодушия природы к человеческому естеству, а значит, это попытка сознания, в котором нет Бога, возвыситься к Св. Духу. По этой дороге вымыслов и поисков идет Коробейников.

В рассказе не раз возникает образ дороги, по которой почти ежедневно вышагивает умирающий Коробейников из санатория - в дачный домик новых знакомых. Прямая номинации в рассказе обрастает символическими приращениями смысла. В символе дороги как жизненного пути время, отпущенное человеку, развертывается как пространственная линия, имеющая начало и конец. Жизнь-путь - движение осознанное, смыслополагающее, где целью становятся поиски смысла пребывания человека в мире. Но трагичность 

пространственные, линейные координаты придает осознание конечности земного бытия. Неизбежно возникает тема смерти, которая в христианской картине мира представляется как переход, преображение, освобождение души, возлетающей к Богу, а в атеистической - как конец, исчезновение и превращение в прах (образ смерти как обездвиженности возникает в русской арготической и просторечной фразеологии - сыграть в ящчик, отбросить копьта, ласты, nоставить шузы в коробку и т.п.). В христианской картине мира линейное время земного бытия преобразуется в категорию вечности как времени, не имеющего ни начала, ни конца, и средоточием этой связи выступает душа, приобщенная к Богу. Душа любого человека, ищущая пути спасения, есть душа странника. Но пушкинское «ум ищет божества, а сердце не находит» стало знамением не только века французского Просвещения, но и двадцатого века, века-безбожника, в котором философия гуманизма достигла своего апогея и вместе с тем своей критической точки. А. Генис, исследуя современное состояние культуры, обращается к точке зрения философаэкзистенциалиста XX века: «Хайдеггер говорил, что мы путаем себя с Богом, забывая о хронологической ограниченности доступного людям горизонта» (Генис 1999. 215). Опыт цивилизации опровергает концепцию безграничных возможностей человеческого разума, восстанавливая в правах тайну мироздания. Человечество убеждается в «неутешительности» системы, которой дано быть «правдоподобной» и отказано в том, чтобы быть истинной.

Душа Коробейникова в поисках какой-либо цепочки, соединяющей его, умирающего, с миром здоровых, живых людей и в то же время - с миром вечности, выискивает сообщения о сверхъестественных событиях; выискивает как приманки для случайного собеседника, подобно тому, как коробейник достает украшенный цветистыми побрякушками гребень, чтобы привлечь внимание прихорашивающейся горожанки. Его душа не находит дороги к 
истинному пламени небесному, а бродит в потемках, высвечивая лишь те или иные мифические символы и факты. Образ бредущего по темному лесу с фонариком старика - вечный образ странника, ищущего дорогу к Всевышнему. В художественном мире Т. Толстой небо недоступно человеку, потому, что сам человек забыл об этой связующей вертикали, и в его тоскующей и оставленной душе место Бога заняли «болиды». Картина поисков дороги к санаторию в ночном мраке становится многозначной и символичной благодаря «навязчиво» всплывающему слову небеса (библейская, возвышенная форма слова), корреспондирующему к заглавию рассказа пламень небесный: «Коробейников направляет луч в небеса, но слабый свет рассеивается. И небеса остаются такими же темными, как и были, разве только верхние веточки да вороньи гнезда освещаются на миг; балуясь, он направляет фонарь к крыльцу, и тогда ничего уже не видно в ночи, только белая звезда на том месте, где стоял Коробейников» (Толстая 2002. 147). Слабый свет указывает на оставленность Богом человеческой души, нестяжение ею Св. Духа. Пламень небесный - этот тот огонь, который не опаляет праведную душу, но сжигает душу мелкую, грешную, не давая ей войти во врата рая. Концепт Смерть в рассказе Толстой “Свидание с птицей» реализуется через семантику фразеологизма: «...о, вот оно, страшное: под руки ведут огромное, ревущее как сирена, задравшее вверх багровую, распухшую морду, это нирыба-ни-мясо, это конец!!!» (Толстая 2002. 83). Словарь дает следующее толкование семантики ФЕ ни-рыба-ни-мясо - 'о ком-либо, не имеющем характерных, отличительных, индивидуальных свойств' (Бирих 1998. 508). Писатель лишь совершает категориальный сдвиг: стертое, обезличенное ничто становится качественной характеристикой смерти-конца, смерти-неперехода. Человечество утратило веру, а без него «мёртвый, пустой мир пропитан серой, глухой, сочащейся тоской» (Толстая 2002. 86). Центральным мотивом, заданным названием сборника рассказов - «Ночь», становится мотив 
бренности и «забвенности» человеческой жизни, которая выхватывается небом из человеческого муравейника, безвозвратно и навсегда вычеркивается из мира. Жизнь ушедшей из земного мира души гаснет в памяти людей вместе с затухающим мерцанием воспоминаний, внезапно вызываемых оставленной вещью: выцветшей фотографией или неуклюжей шляпкой.

T. Толстая не может смириться - нет, не со смертью даже, - а с забвением, когда «смыкается световой коридор, как сгущается тьма, как во тьме пламень небесный нашаривает свою жертву» (Толстая 2002. 158). Она стремится продлить, достроить тот «световой коридор», где смерть окажется лишь движением по вертикали. И писатель в пространстве художественного текста способен раздвинуть границы мира символами, которые оберегают память человечества.

Вернемся к словарным дефинициям, которые разводят слова пламя и пламень только по стилистическим (пламень - высок.) и нормативнохронологическим (пламень - устар.) параметрическим признакам. Термин «стилистическая возвышенность» часто представляется самодостаточным, не требующим развернутого лингвистического толкования. Традиционно выделение высокой стилевой окраски книжной лексики не связывается непосредственным образом ни с эмоционально-оценочным компонентом значения языкового знака, ни с его функционально-стилевой прикрепленностью. Отнесение языковой единицы к тому или иному стилевому регистру ставится в зависимость от употребляемости единицы в определенной коммуникативной ситуации, т.е. касается только социально-речевых ролей коммуникантов и прагматической направленности употребления единицы. Считается, что разговорные элементы характеризуют речь как непринужденную, привычно-бытовую, а противопоставленные им высокие как эмоционально-приподнятую, торжественную. Выделяют такие особенности высокого стиля, как торжественность, патетичность, поэтичность. 
По нашему мнению, книжность и возвышенность лексической единицы определяются привязанностью к определенному литературному и (или) мифологическому контексту. Книжность проявляется в корреспондировании единицы к культурно обработанным символам, образам, метафорическим моделям, которые конденсируют в себе черты определенных дискурсов антично-мифологического, литературно-авторского, религиознохристианского, и в этом случае к семантике языкового знака подключаются все значимые для данного корпуса текстов смыслы. Таким образом единица пламень (небесный) вбирает в свою семантику смыслы, значимые для религиозно-христианского мировидения, и при включении в художественный текст «отдает» эти дискурсивные наращения смысла семантике нового текста, значительным образом углубляя и расширяя его ассоциативным включением интертекстуальных связей. Мы говорим о том, что лексема пламень становится ключевым знаком художественного текста, подключающим значительное семиотическое пространство христианской культуры и обогащающим текст культурными смыслами, значимыми для национального мировидения. При сопоставлении пламени с более современным вариантом - словом пламя, обнаруживаем, что последнее обладает более предметным значением в большинстве контекстов и соотносится с понятием «огонь, подымающийся над горящим предметом» или «светящийся пар или газ, выделяемый некоторыми веществами при горении» (Ефремова 2000): «В темноте пламя и взрывы под трамваем были особенно красивы и радовали сердца хулигановмалышат» (Эд. Лимонов. У нас была Великая Эпоха // НКРЯ). - «Пламя взметнулось, и осветились горбатый серый брезент и тонкая женская рука рядом на гальке» (Ю. О. Домбровский. Факультет ненужных вещей, часть 5 // НКРЯ). Также во многих контекстах используется метонимический перенос, в результате которого создается описание свойств объекта, уподобляющих его пламени по приписываемым этому объекту признакам (цвету, жару, свету, 
интенсивности горения): «Это был старый Ёжикин дуб у крыльца с мощной кроной, только корни его языками пламени били по синеве» (С. Козлов. Как Ёжик с Медвежонком спасли Волка // НКРЯ). - «Солнце садилось, ветер всё крепчал, закат разгорался пурпуром, и по мере того как пламя разливалось по небу, - синева моря становилась всё глубже и холоднее» (В.Г. Короленко. Мгновение // НКРЯ). Слово пламя соотносится с рукотворным огнем, земным огнем - огнем очага, грозовым огнем, огнем Солнца, а также огнем, живущим, по древним представлениям, в теле человека или животного. В тех метафорических переносах, которые встречаются в художественных текстах, образы довольно редко связываются с христианской картиной мира.

Можно также обратить внимание на то, что слово пламя организует метафорические модели, которые означивают события или процессы, которые быстрым способом охватывают массы людей, меняя в корне (чаще разрушая или уничтожая вовсе их мир, прежний образ жизни, идеологию), подобно тому, как огонь, переходя от объекта к объекту, охватывает стремительно большую территорию (пламя войны, пламя революции и т.п.): «И вдруг пламя стахановского движения объяло всю страну» (И.В. Сталин. Речь на Первом Всесоюзном совещании стахановцев // «Правда», 1935.11.22 // НКРЯ).

Лексемы пламя и пламень равно встречаются в значении «душевный подъем, воодушевление» в контекстах, где автору необходимо указать на интенсивность эмоций. В этой модели носитель эмоций означивается как пассивный объект, который не в силах противостоять захватывающему его душу чувству: «- А ты б сказала... - смех от Даши перебросился к Оленьке и охватывал её как пламя, - ты б сказала... ты б сказала...! - Но никак она не могла выговорить своего предложения и, хохоча, опустилась на кровать, однако не мня разложенного там костюма» (Ал. Солженицын. В круге первом // НКРЯ). - «В громадных серых глазах её таился, как под пеплом, огонь, дунь на них - и пламя охватит всё лицо, а веснушки запылают, языки пламени 
лизнут лоб и волосы...» (Ан. Азольский. Облдрамтеатр // НКРЯ). - «Смотрю на нее дремлющую, без кровинки в лице... какой же пламень должен гореть в ее душе, чтобы заставить тело жить, дышать!» (Татьяна Окуневская. Татьянин день // НКРЯ).

\section{Заключение}

Изучение контекстов употребления слова пламень позволяет сделать вывод о том, что его концептуальное поле значительным образом расширяет его лексическое значение, представленное в толковых словарях, поскольку подключает библейскую семиосферу, представляющую дихотомическое восприятие мира и человека, выстраивающую вертикаль от высокого, горнего, божественного, благого до низкого, дьявольского, означенного как грехопадение. Коннотативно-оценочные смыслы в семантике пламени базируются на оппозиции, существующей в христианской картине мира как пламени Божественного света и благодати и пламени, карающего за грехопадение. Пламень Божественный предстает животворным источником, дарующим энергию, творческое дыхание и любовь человеческой душе, грехопадение же приближает падшую душу к адскому пламени, т.е. осмысляется как саморазрушение и страдание.

\section{Литература}

1- Бирих А.К., Мокиенко В.М., Степанова Л.И. (1998). Словарь русской фразеологии. Историко-этимологический справочник. - М.: Фолио-Пресс.

2- Генис А. (1999). Иван Петрович умер. Статьи и расследования. - М.: Новое литературное обозрение.

3- Гершензон М.О. (1990). Мудрость Пушкина // Пушкин в русской философской критике: Конеи XIX - первая половина XX в. - М.: Книга. - С. 207 - 243.

4- Ефремова Т.Ф. (2000). Новый словарь русского языка. Толковословообразовательный. - M.: Русский язык // URL: https:/lexicography. online/explanatory/efremova/п/пламя (Дата обращения: 11.04.2021). 
5- Нациинальный корпус русского языка - НКРЯ // URL: https://ruscorpora.ru/new/search-main.html (Дата обращения: 11.04.2021).

6- Охоцимский А.Д. Образ-парадигма Божественного Огня в Библии и в христианской традищии // Иеротопия [сайт]. - URL: http://hierotopy.ru/ru/?page_id=214 (дата обращения 07.03.2021).

7- Словарь русского языка: В 4-x m. - Т. 3 / РАН, Ин-т лингвистич. исследований; Под ред. А.П. Евгеньевой. - URL: http://feb-web.ru/feb/mas/mas$\mathrm{abc} / 16 / \mathrm{ma3} 13201 . \mathrm{htm} ? \mathrm{cmd}=0$ \&istext=1 (дата обращения 07.03.2021).

8- Толстая Т.Н. (2002). Ночь: Рассказы. - М.: Подкова.

\section{Bibliography}

1- Birih A.K., Mokienko V.M., Stepanova L.I. (1998). Slovar' russkoj frazeologii. Istoriko-jetimologicheskij spravochnik. - M.: Folio-Press.

2- Genis A. (1999). Ivan Petrovich umer. Stat'i i rassledovanija. - M.: Novoe literaturnoe obozrenie.

3- Gershenzon M.O. (1990). Mudrost' Pushkina // Pushkin v russkoj filosofskoj kritike: Konec XIX-pervaja polovina XX v. - M.: Kniga. - S. 207 - 243.

4- Efremova T.F. (2000). Novyj slovar' russkogo jazyka. Tolkovo-slovoobrazovatel'nyj. - M.: Russkij jazyk // URL: https://lexicography.online/explanatory/efremova/ p/plamja (Data obrashhenija: 11.04.2021).

5- Nacional'nyj korpus russkogo jazyka - NKRJa // URL: https://ruscorpora.ru/new/ search-main.html (Data obrashhenija: 11.04.2021).

6- Ohocimskij A.D. Obraz paradigma Bozhestvennogo Ognja v Biblii $i$ v hristianskoj tradicii // Ierotopija [sajt]. - URL: http://hierotopy.ru/ru/?page_id=214 (data obrashhenija 07.03.2021).

7- Slovar' russkogo jazyka: V 4-h t. - T. 3 / RAN, In-t lingvistich. issledovanij; Pod red. A.P. Evgen'evoj. - URL: http://feb-web.ru/feb/mas/mas-abc/16/ ma313201.htm? $\mathrm{cmd}=0 \&$ istext $=1$ (data obrashhenija 07.03.2021).

8- Tolstaja T.N. (2002). Noch': Rasskazy. - M.: Podkova.

\section{HOW TO CITE THIS ARTICLE}

Zakharova N. N. (2021). The Heavenly Flame: The Christian

Picture of the World and Modeling of the Image in the Literary

Text. Issledovatel'skiy Zhurnal Russkogo Yazyka I Literatury,

9(2), 151-167.

DOI: $10.52547 /$ iarll.18.151

URL: https://www.journaliarll.ir/index.php/iarll/article/view/205 
بارقهاى آسمانى: تصوير مسيحى از جهان و مدلسازى تصوير در متون ادبى

$$
\begin{aligned}
& \text { نادزدا نيكالايونا زاخارواء" } \\
& \text { دانشيار، دانشكاه دولتى توَلا، } \\
& \text { تولا، توسيه. }
\end{aligned}
$$

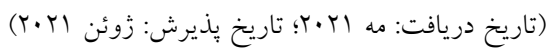

وازهها در متون ادبى مى تو انند بهعنوان نماد و نشانه بهكار روند، زير إزرفيـت معنـايى آنهـا





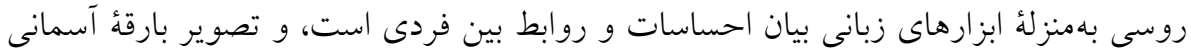



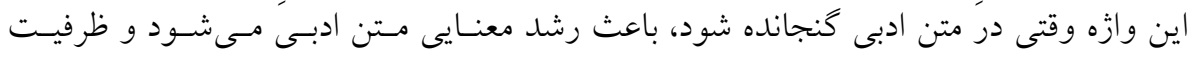



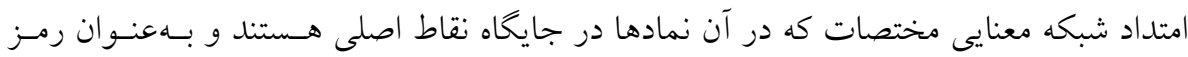

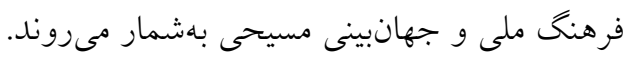

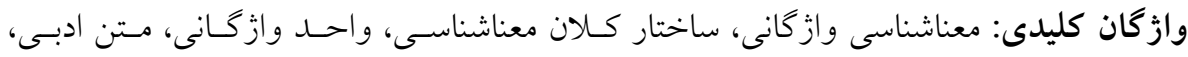
تصوير مسيحى از جهان، نماد. 